\title{
Cutaneous Adverse Drug Reactions-A Study of Clinical Patterns, Causality, Severity \& Preventability
}

\author{
Dr. Reena Verma ${ }^{1}$, Dr.Shreyansh Tiwari ${ }^{2}$, Dr.CM Gupta ${ }^{3}$ Dr. Nitin Verma ${ }^{4}$ \\ ${ }^{1}$ (Department of Pharmacology, LN medical college \&JK hospital,research centre, India) \\ ${ }^{2}$ (Department of Dermatology , LN medical college \& JK hospital, research centre, India) \\ ${ }^{3}$ (Department of Dermatology, LN medical college \& JK hospital, research centre, India) \\ ${ }^{4}$ (Department of Paediatrics, NICU In charge, Bansal hospital, India)
}

\begin{abstract}
:
Aim- to study CADRs for clinical patterns, risk factors, causality, severity \&preventability.

Material \& methods- A prospective study was undertaken in a 750 bedded tertiary care teaching hospital of central India. Patients with CADRs presenting primarily or referred from other departments were enrolled after being diagnosed by consultant dermatologist. Causality, preventability and severity were analyzed \&Other parameters like male to female ratio, most common class of drug, individual drug causing CADR, common types of CADRs, were studied.

Results-34 cases were enrolled for the study in the duration of march2014 to june2014.Female predominance (55.88\%) with $35.2 \%$ patients falling in 21-30years age group. Most frequently occurring CADR was maculopapular rash (29.4\%) followed by fixed drug eruption (23.5\%), photosensitivity (20.5\%), SJS (17.6\%) \& $8.8 \%$ acneiform eruptions, erythema multiforme $(2.9 \%) \&$ toxic epidermal necrolysis or $\operatorname{TEN}(2.9 \%)$.Antimicrobial drugs (56\%) followed by analgesic/anti- inflammatory/antipyretic (17.6\%) and then antiepileptic drugs about (15\%) were the drug classes involved. Other drugs like tryptomer\& isotretinoin accounted for about $11.7 \%$ of CADRs. Fluoroquinolones accounted for highest percentage (20.5\%) of CADRs.

Conclusions - Female predominance was seen. Flouroquinolones being the most common offending drug \& diclofenac \& aceclofenac among the anti-inflammatory, analgesics class. Causality assessment also resulted in high score of definite category. These variations may be explained by the differences in drug usage patterns and short duration of the study.
\end{abstract}

Keywords: CADRs-cutaneous adverse drug reactions, causality, Naranjo's algorithm.

\section{Introduction}

Indiscriminate use of drugs, inflow of new drugs in the market, almost to the level of everyday a new drug entering the market, lack of ADR reporting culture has resulted in rise of ADR incidence. Along with taking in the account that most of these ADRs remain unknown and more importantly underreported, comprehensive information regarding their incidence, severity ,preventability and the effects on health system is often not available.ADRs may range from mild reaction to severe ones \& may be even fatal. Doctors should be aware and oriented to identify the condition earliest and manage appropriately as early diagnosis and treatment has a substantial effect on the management and final outcome. Indiscriminate use of drugs, polypharmacy and multi organ involvement often poses problem in identifying the responsible drug.

An adverse drug reaction (ADR) has been defined as any noxious, unintended and undesired effect of a drug which occurs at a dose used in humans for prophylaxis, diagnosis, therapy or modification of physiological functions [1]. Adverse drug reactions account for significant morbidity and mortality in health sector. An Adverse cutaneous Drug Reaction (ACDR) caused by a drug is any undesirable change in the structure or function of the skin, its appendages or mucous membranes and it encompasses all adverse events related to drug eruption, regardless of the etiology.[2] Adverse drug reactions (ADR) are rated as the fifth leading cause of death among all diseases. Approximately 5-8\% of all hospitalization worldwide is due to ADR. Cutaneous adverse drug reactions (CADR) are the commonest ADRs (30-45\%) and responsible for about $2 \%$ of hospital admissions.[3]Approximately $2-7 \%$ of these may be severe.[4]In India, CADR account for $2-5 \%$ of all inpatients, while it affects $2.6 \%$ of outpatients.[5] Many ADRs are commonly known and are present in literature but some are rare and may present without warning. Cutaneous drug eruptions are one of the most common types of adverse reaction to drug therapy, with an overall incidence rate of $2-3 \%$ in hospitalized patients. [6,7]

Almost any medicine can induce skin reactions, and certain drug classes, such as non-steroidal antiinflammatory drugs(NSAIDs), antibiotics and antiepileptic drugs, have drug eruption rates approaching 1$5 \%$.[8]Most of the cutaneous drug reactions are not serious but some are severe and potentially lifethreatening. Serious reactions include angioedema, erythroderma, Stevens-Johnson syndrome and toxic 
epidermal necrolysis(TEN). Drug eruptions can also occur as a result of multiorgan involvement, as in druginduced systemic lupus erythematosus. Drug reactions can be classified into immunologic and nonimmunologic etiologies .The majority about $75-80 \%$ of adverse drug reactions are predictable \& non-immunological in origin, the remaining $20-25 \%$ of adverse drug events are immune-mediated or unpredictable reactions. Skin reactions as a result of non-immunological causes are more common and include cumulative toxicity, overdose, photosensitivity, drug interactions, and metabolic alterations. [9]Many commonly used drugs can produce serious cutaneous ADRs which can lead to morbidity and some may even prove lethal. The high incidence of ADRs, poor ADR reporting, meager data on the ADR profile, probability, severity and causality assessment makes it difficult to ensure safety of drug usage. To establish a final decision of causality, a standardized method should be used which will result in consistent, accurate and reproducible identification of ADRs. [10]

WHO defines Pharmacovigilance as the science and activities relating to the detection, assessment, understanding and prevention of adverse effects or any other drug related problems.ADR burden the health system by not only increasing the mortality \& morbidity but also the expenses. Science of Pharmacovigilance is accountable to identify, appraise, comprehend and avert ADRs with the eventual mean to develop secure and coherent utilization of medication [11][12][13][14].Current methods of Pharmacovigilance possess certain constraints reminiscent of under reporting, inability to find the incidence rate, size of the population exposed and bias in collection of drug exposure[11][15][16][17]. Pharmacovigilance gives a vital measure of the burden of drug induced morbidity and approximately half of ADRs could be averted with better prescription care [18] [19] [20].

The pattern of cutaneous adverse drug eruptions and the drugs responsible for them keep changing every year. There are various factors associated with cutaneous adverse drug reactions like many studies have reported incidence to be more in males than females. [21,22].The presentations may also differ in different studies. some studies found maculopapular rash to be most common type of cutaneous ADR.[22] Some other studies found fixed drug eruptions as the most common drug eruption followed by maculopapular rash and urticaria[21,23]. Offending drugs may also vary. Some studies have reported antimicrobials as the major group followed by antiepileptics and NSAIDs. [22, 23, 5]Causality assessment may also show differences. A study has reported $5 \%$ definite, $55 \%$ probable and $40 \%$ possible cutaneous ADRs. [24]

The wide \& indiscriminate use of drugs has increased the incidence \&modes of presentation of CADRs.Underreporting of ADRs is the major problem due to various reasons including workload, lack of orientation, disinterest. These reactions may differ with different classes. Generating data is essential to understand the pattern of CADRs of different classes and generating information regarding offending drugs. This will help the doctors to ensure safe drug usage and be aware of offending drugs .So that, early diagnosis can be made based on this information and treatment be instituted as soon as possible. Differences in results of various studies points to the various factors associated with CADRs. Physician's preferences, patterns of drug usage, local ethnic, regional \& individual variations may account for these differences $\&$ need to be studied.

\section{Objectives}

The objective of this study was to identify and quantify the risk factors associated with CADRs\& characterize the clinical pattern of ADRs reported in a tertiary care teaching hospital in the department of dermatology JK hospital, Bhopal (both departmental \&referred cases). The present study was undertaken to characterize the pattern of CADRs. The study was conducted based on the CADRs reported between march2014and june2014 (4months) in the department of dermatology. Evaluation of the data was done for various parameters which included patient demographics, drug and reaction characteristics, and outcome of these ADRs. Assessment was also done for predisposing factors, causality, severity, preventability.

\section{Material \& methods}

A prospective study was undertaken with follow up of patients in the department of Pharmacology \& department of Dermatology of LN Medical College \& JK Hospital, a 750 bedded tertiary care teaching hospital in the duration of march2014 to june2014. All the patients who reported in dermatology OPD were screened and patients with suspected cutaneous ADRs presenting primarily in the dermatology OPD or referred from other departments of the hospital during the study period were included in the study. Study protocol was approved by institutional ethics committee. Identifiers were the investigators, discretion of information acquired was secured $\&$ all the measures to maintain confidentiality were undertaken, during the study. Consent of the patient was taken for the enrollment in the study. Suitable study design for ADR profile study was developed for data compilation. Unlikely, conditional or unassessible cases were excluded from the study. The diagnosis of the cutaneous ADR was based on history of drug exposure, clinical findings and exclusion of other similar disorders and was done by the consultant dermatologist. No rechallenge was done and appropriate treatment was given to patient after diagnosis of ADR. 


\subsection{Analysis}

All the results were calculated in percentages and proportions. Adverse drug event patterns, Common drug classes accounting for ADRs, drugs involved, common presentations were part of the study. Causality assessment was done by by Naranjo's algorithmic scale [26] which is the most common assessment tool of $\mathrm{ADR}$, and verifies the chances of whether an ADR is essentially due to the drug or it is the result of other causes, the likelihood is consigned by the score, termed as definite, probable or possible [25]. Severity of ADR was assessed by Modified Hartwig and Siegel Scale [26]. Preventability was assessed by Modified Schumock and Thornton Scale[27][28].

\section{Causality-assessment}

The extent of relationship between suspected ADR and the drug therapy was assessed using the Naranjo's algorithmic scale. [25]

\begin{tabular}{|c|c|}
\hline Score & Interpretation of Scores \\
\hline $\begin{array}{l}\text { Total } \\
\text { Score } \\
\geq 9\end{array}$ & $\begin{array}{l}\text { Definite. The reaction (1) followed a reasonable temporal sequence after a drug or in which a toxic drug level had been } \\
\text { established in body fluids or tissues, (2) followed a recognized response to the suspected drug, and (3) was confirmed by } \\
\text { improvement on withdrawing the drug and reappeared on re exposure. }\end{array}$ \\
\hline $\begin{array}{l}\text { Total } \\
\text { Score } \\
5 \text { to } 8\end{array}$ & $\begin{array}{l}\text { Probable. The reaction (1) followed a reasonable temporal sequence after a drug, (2) followed a recognized response to } \\
\text { the suspected drug, (3) was confirmed by withdrawal but not by exposure to the drug, and (4) could not be reasonably } \\
\text { explained by the known characteristics of the patient's clinical state. }\end{array}$ \\
\hline $\begin{array}{l}\text { Total } \\
\text { Score } \\
1 \text { to } 4\end{array}$ & $\begin{array}{l}\text { Possible. The reaction (1) followed a temporal sequence after a drug, (2) possibly followed a recognized pattern to the } \\
\text { suspected drug, and (3) could be explained by characteristics of the patient's disease. }\end{array}$ \\
\hline $\begin{array}{l}\text { Total } \\
\text { Score } \leq 0\end{array}$ & Doubtful. The reaction was likely related to factors other than a drug. \\
\hline
\end{tabular}

\section{Severity assessment by Modified Hartwig and Siegel Severity assessment scale}

Severity of the reaction was assessed by using the Modified Hartwig and Siegel Severity assessment scale [26] and the severity is broadly categorized into "mild," moderate and "severe for each ADR. The suspected ADR is "mild" when "an ADR occurs but requires no change in treatment with the suspected drug" or the ADR requires that treatment with the suspected drug be held, discontinued, or otherwise changed. No antidote or other treatment requirement was required. No increase in length of stay (LOS). The suspected ADR is "moderate" when "the ADR requires treatment with the suspected drug be held, discontinued, or otherwise changed" and/or "an Antidote or other treatment was required. No increase in LOS" or "any level 3 ADR that increases LOS by at least 1 day," or "the ADR was the reason for the admission." The suspected ADR is "severe" when "Any level 4 ADR that requires intensive medical care or the adverse reaction caused permanent harm to the patient or the adverse reaction either directly or indirectly led to death of the patient."

\section{Preventability assessment by schumock and Thornton scale}

All the reported ADRs were assessed for their preventability using the modified criteria of Schumock and Thornton's by Lau et al., [28]and were categorized into "Definitely preventable," "probably preventable," and "not preventable."

\section{Results}

A total of 35cases of suspected cutaneous ADRs were recorded during the period of study, out of which 1 case was excluded because the offending drug was not identified as the patient was taking ayurvedic (alternative) medicine simultaneously. The remaining 34 cases were analyzed. Out of 34 patients, 15 cases $(44.11 \%)$ were males and 19 cases $(55.88 \%)$ were females. Maximum patients belonged to the age group of 21 $30(35.2 \%)$ followed by $31-40(20.15 \%)$ and $41-50(17.6 \%)$. The most common pattern of cutaneous ADR observed was maculopapular rash (29.4\%) followed by fixed drug eruption (23.5\%). Other types of cutaneous ADRs that were seen included, $20.5 \%$ cases of photosensitivity, SJS(17.6\%)\& $8.8 \%$ acneiform eruptions, erythema multiforme $(2.9 \%) \&$ toxic epidermal necrolysis or TEN(2.9\%). The most common group of offending drugs responsible for causing cutaneous ADRs were antimicrobial drugs $(56 \%)$ followed by analgesic/antiinflammatory/antipyretic (17.6\%) and then antiepileptic drugs about(15\%) .Other drugs like tryptomer\& isotretinoin accounted for about $11.7 \%$ of CADRs.

Causality assessment(Naranjo's scale)-34 cases of cutaneous ADRs were analyzed. After assessment, 4 cases (18.88\%) scored definite, 25cases (73.52\%) were of probable score whereas 5 cases $(14.70 \%)$ were in possible score category.Unlikely, conditional or unassessible cases were excluded from the study. 
Severity assessment using Modified Hartwig and Siegel scale -Assessment shows 23 (67.64\%) cases of mild grading, $10(29.41 \%)$ of moderate and $1(2.9 \%)$ case of severe grading.

Preventability assessment using Schmock \&Thornton scale-6 cases (17.64\%) were found to be definitely preventable whereas 28 cases $(82.35 \%)$ were probably preventable.

\section{Discussion}

Cutaneous ADRs have a varied presentation in clinical patterns, distribution \&response to treatment. Total 34 cases were reported during study period, out of which 15 (44.11\%) were males and $19(55.88 \%)$ were females. This is slightly different with the findings of many studies where male predominance has been observed.[21][22]Though there are studies which have reported female predominance like a study conducted in a tertiary care hospital of south India.[23] The majority of the patients belonged to the age group of 21-30 years (35.2\%) followed by 31-40 (20.15\%) years, which is in accordance with the another study that also reported similar observations.[22] Another study observed that adults aged 20-49 years were at greatest risk of antibiotics-related drug eruptions, probably due to increased exposure to antibiotics.[30] However, two other studies noted that the elderly are more commonly affected.[30][31]Elderly have more incidences of ADRs. This may be due to the increased use of medications by the elderly, increased potential for drug-drug interactions, and altered drug handling by the body. The difference in various studies may be related to the regional variation in the health care seeking behavior of the population.[32] Of the various types of cutaneous ADRs seen in this study, maculopapular rash (29.4\%) are the commonest one ,this is similar to observation of another study conducted in north Indian hospital.[22] followed by fixed drug eruptions $(23.5 \%)$,photosensitivity $(20.5 \%)$ and SJS(17.6\%),acneiform eruptions(8.8\%),erythema multiforme(2.9\%)\&TEN(2.9\%). Some other studies found fixed drug eruptions as the most common drug eruption followed by maculopapular rash and urticaria.[29][31]This variation could be due to variation in drug usage, factors related to local patterns of drug use and individual susceptibilities.

Most frequently reported adverse drug reactions were due to antimicrobial agents in 19cases (55.88\%), followed by analgesic/anti-inflammatory/antipyretics in 6 cases $(17.6 \%)$ and anti-epileptics in 5cases $(14.7 \%)$ Study carried out in south India also reported similar results in their study whereas some studies have reported antimicrobials as the major group followed by antiepileptics and NSAIDs .[22][23][5]

In the present study, among antimicrobials, flouroquinolones(7 cases, $20.5 \%)$ were the most common drugs causing cutaneous ADRs followed by antitubercular drugs(AKT-4) responsible in about $6(17.6 \%)$ cases. In analgesic/anti-inflammatory/antipyretics group Diclofenac \& aceclofenac together were responsible for 4 (11.7\%) cases, ibuprofen also accounted for 5.8\% cases. Among antiepileptics, phenytoin was the drug responsible for CADRs in $11.7 \%$ cases followed by valproate in $2.9 \%$.

In this study, we used Naranjo's causality assessment scale. Out of 34 cases of cutaneous ADRs studied the dechallenge was done in all cases. Out of which 4 cases $(11.76 \%)$ were definite and 25 cases $(73.52 \%)$ were probable whereas remaining 5 cases $(14.70 \%)$ were considered to fall in possible category .

Another study which included inpatients and used Naranjo's scale for causality assessment reported $2 \%$ definite, $80 \%$ probable and $18 \%$ possible reactions. [32] The variation in results of different studies may be due to various factors affecting the drug usage, physician's drug preferences and different scales used for causality assessment. In our study the short duration of study may be an important factor for variation in results.

\section{Drawbacks}

Short duration of the study is a limitation of the study. So variations are more on comparison with the results of other studies. Though differences in the pattern of drug use, associated diseases, local factors \& individual variations can also affect the outcomes. Rechallenge was not done due to ethical considerations which may again influence the scoring and the results. 
VII. Figures

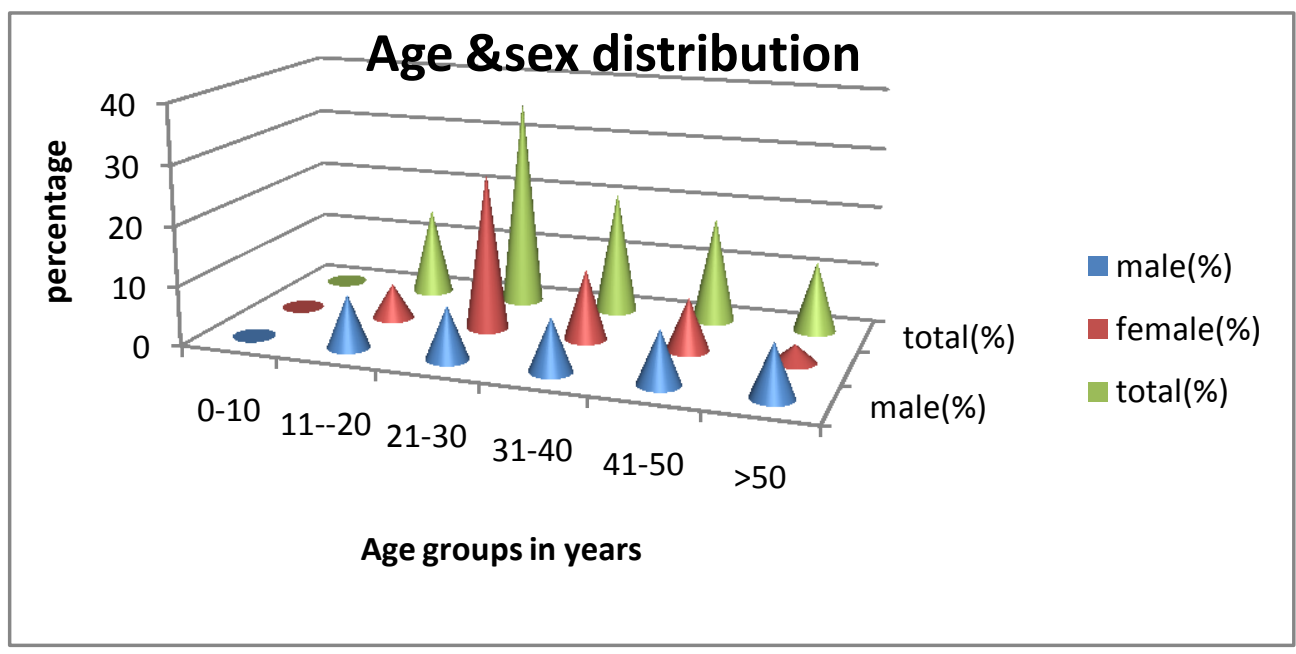

Fig.1

\section{sex distribution in percentage}

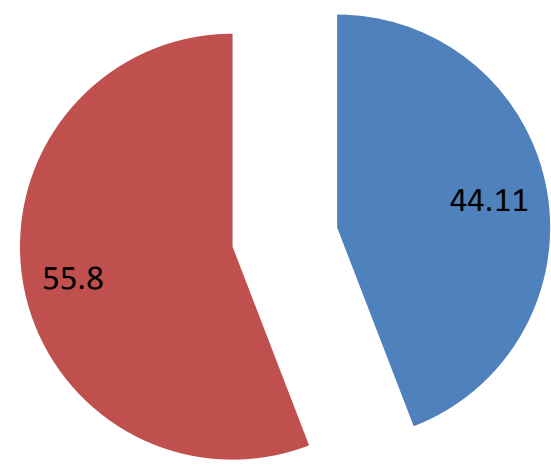

Fig-2

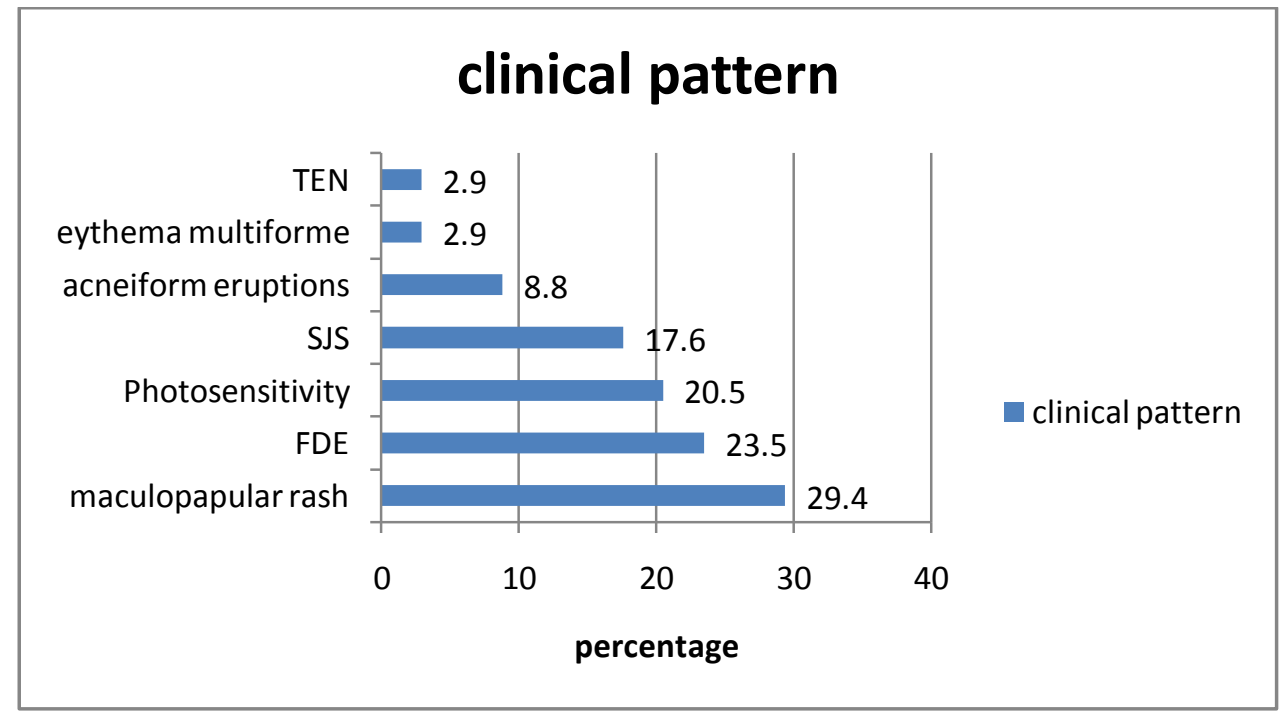

Fig.3 


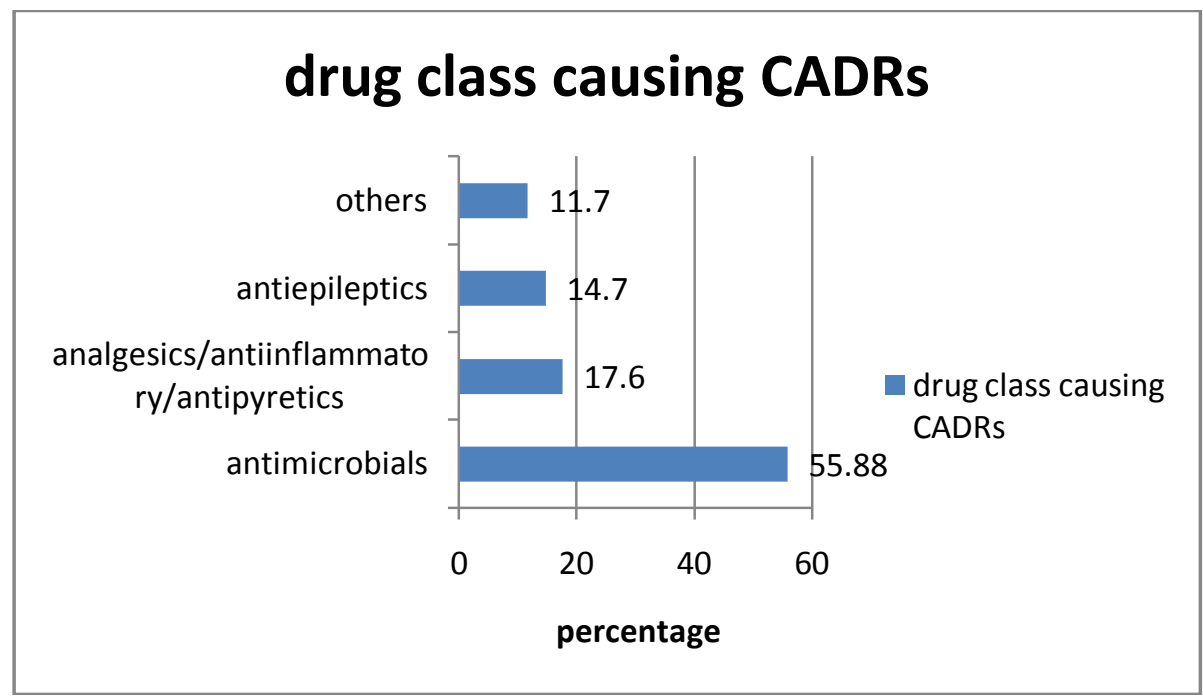

Fig-4

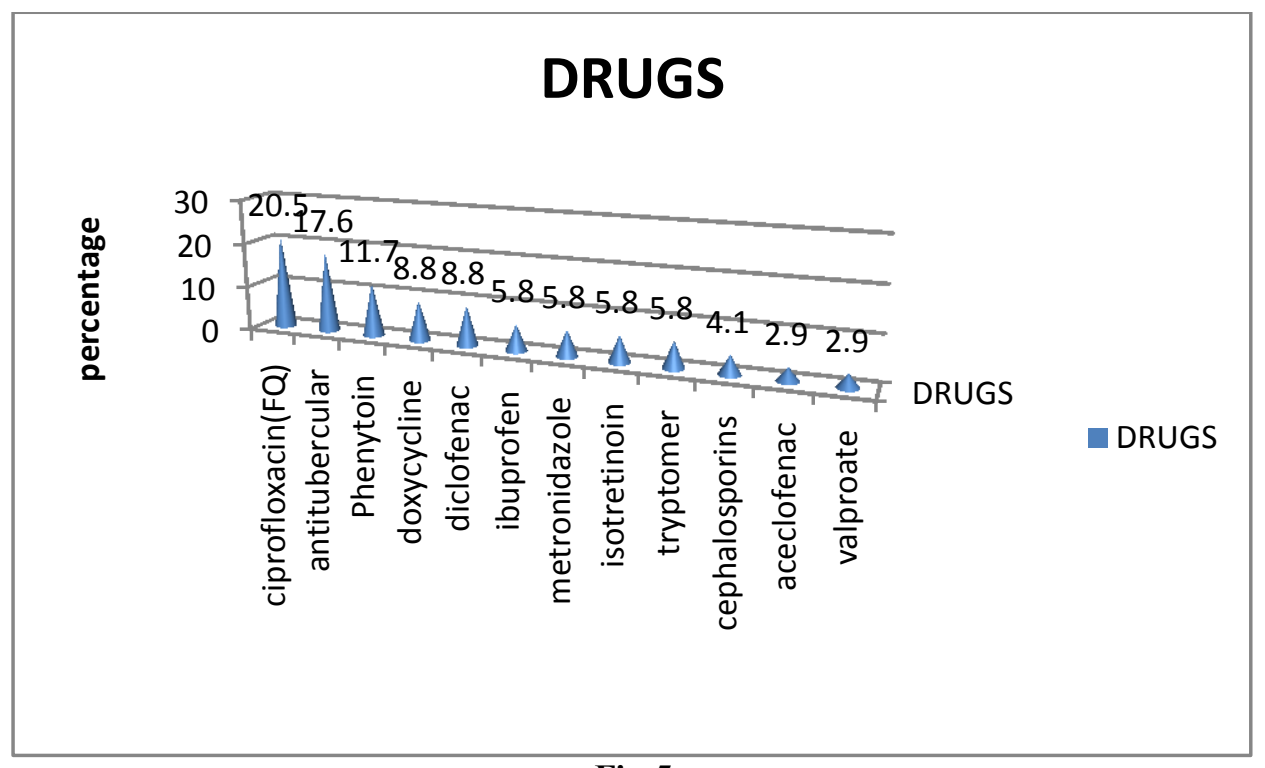

Fig-5

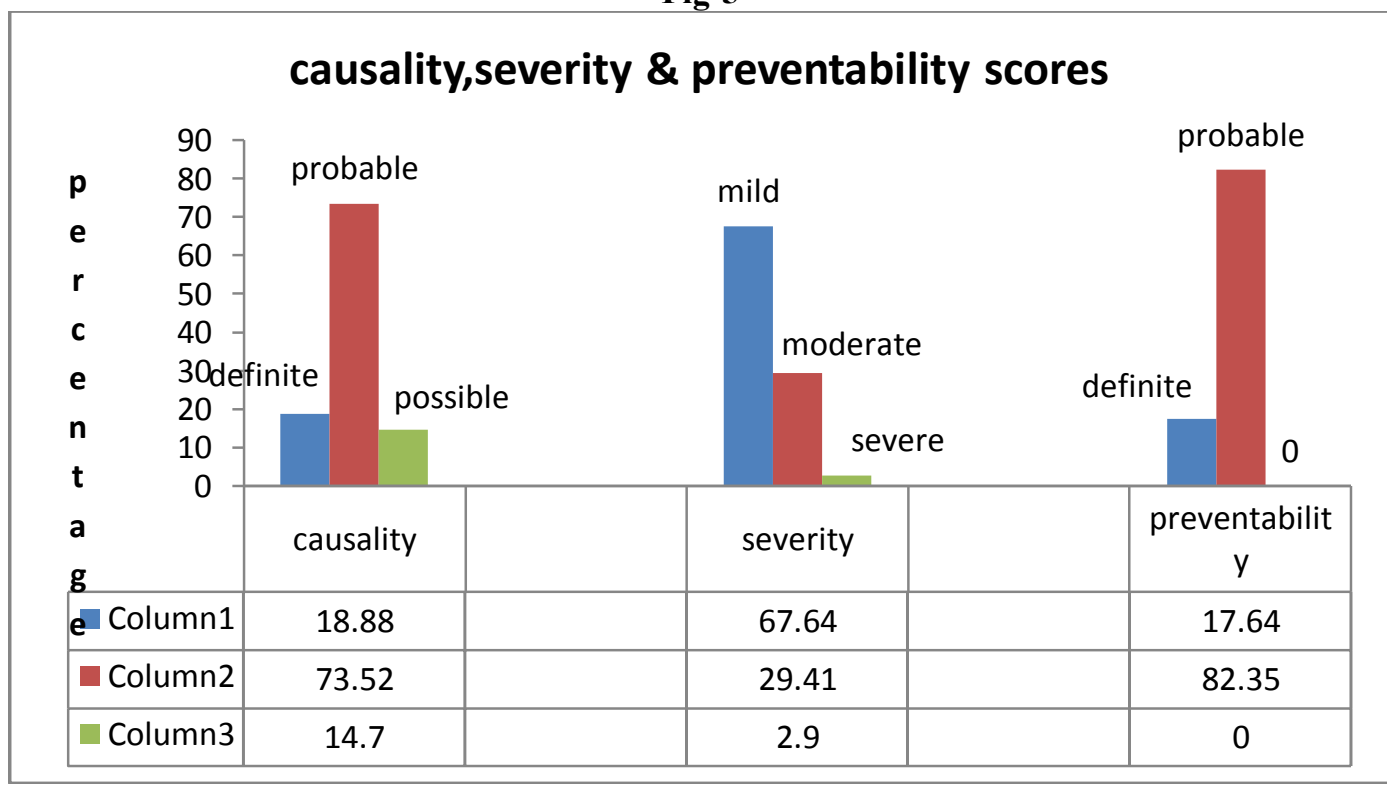

Fig-6 


\section{Conclusion}

There are variations in the results in comparison to other studies like female predominance, offending drugs like among antimicrobials flouroquinolones were found to be commonly involved. Among analgesics, antiinflammmatory group diclofenac \& aceclofenac were commonly responsible drugs. Causality assessment also resulted in high score of definite category. These variations may be explained by the differences in drug usage patterns and short duration of the study which is also accepted as a limitation of the study .But it definitely gives a snapshot of the problem which can be elaborated to a detailed study with a bigger sample size \&longer duration of the study. Burden of the problem was addressed and different clinical patterns \&presentations were studied. Strict ADR monitoring \&reporting will help generate data about the CADRs, thus, helping in their early diagnosis and management.

\section{Acknowledgement}

We gratefully recognize the help of Dr. Vishal Bankwar, associate professor, community medicine, LN medical college. Also we sincerely thank Dr Parag Sharma, professor \& head Department of pharmacology \& Dr.Niket Rai, assistant professor, Pharmacology for their constant support.

\section{Conflict of interest \\ None declared}

\section{References}

[1]. World Health Organization. Collaborating Centre for International Drug Monitoring. Geneva: World Health Organization. 1984, WHO publication DEM/NC/8

[2]. Nayak S, Acharjya B. Adverse cutaneous drug reaction. Indian J Dermatol 2008; 53:2-8. 1. Breathnach SM, Hintner H. Adverse Drug Reactions and the Skin. Oxford:Blackwell Scientific, 1992.

[3]. Valeyrie-Allanore L, Sassolas B, Roujeau JC. Drug-induced skin, nail and hair disorders. Drug Saf. 2007;30:1011-1030.

[4]. Ajayi FO, Sun H, Perry J. Adverse drug reactions: a review of relevant factors. J Clin Pharmacol. 2000;40:1093-1101.

[5]. Chatterjee S, Ghosh AP, Barbhuiya J, Dey SK. Adverse cutaneous drug reactions: a one year survey at a dermatology outpatient clinic of a tertiary care hospital. Indian J Pharmacol.2006;38:429-431.

[6]. Crowson AN, Brown TJ, Magro CM. Progress in the understanding of the pathology and pathogenesis of cutaneous drug eruptions. Am J Clin Dermatol2003; 4: 407-428.

[7]. Wolkenstein P, Revuz J. Drug-induced severe skin reactions. Drug Safety 1995;13: 56-68.

[8]. Bigby M. Rates of cutaneous reactions to drugs. Arch Dermatol 2001; 137:765-770.

[9]. McKenna JK, Leiferman KM. Dermatologic drug reactions. Immunol Allergy Clin North Am 2004; 24: $399-423$.

[10]. Kramer MS, Leventhal JM, Hutchinson TA, Feinstein AR. An algorithm for the operational assessment of adverse drug reactions.I. Background description and instruction for use. J Am Med Assoc 1979;242:623-32.

[11]. Montastruc J.L., Sommet A., Lacroix I., Olivier P., Durrieu G., Damase C., Lapeyre-Mestre M., Bagheri H. Pharmacovigilance for evaluating adverse drug reactions: value, organization, and methods. Joint Bone Spine. 2006;73:629-632

[12]. Arulmani R., Rajendran S.D., Suresh B. Adverse drug reaction monitoring in a secondary care hospital in South India. Br. J. Clin. Pharmacol. 2008;65:210-216

[13]. Avery A.J., Anderson C., Bond C.M., Fortnum H., Gifford A., Hannaford P.C., Hazell L., Krska J., Lee A.J., McLernon D.J., Murphy E., Shakir S., Watson M.C. Evaluation of patient reporting of adverse drug reactions to the UK 'Yellow Card Scheme': literature review, descriptive and qualitative analyses, and questionnaire surveys.Health Technol. Assess. 2011;15:1-234.

[14]. Mehta U., Durrheim D.N., Blockman M., Kredo T., Gounden R., Barnes K.I. Adverse drug reactions in adult medical inpatients in a South African hospital serving a community with a high HIV/AIDS prevalence. Prospective observational study. Br. J. Clin. Pharmacol. 2008;65:396-406.

[15]. Wasserfallen J., Livio F., Buclin T., Tillet L., Yersin B., Biollaz J. Rate, type, and cost of adverse drug reactions in emergency department admissions. Eur. J. Intern. Med.2001;12:442-447

[16]. Routledge P.A., O’Mahony M.S., Woodhouse K.W. Adverse drug reactions in elderly patients. Br. J. Clin. Pharmacol. 2003;57:121-126

[17]. Smyth R.M., Gargon E., Kirkham J., Cresswell L., Golder S., Smyth R., Williamson P. Adverse drug reactions in children-a systematic review. PLoS ONE.2012; 3:e24061.

[18]. Chien J.Y., Ho R.J. Drug delivery trends in clinical trials and translational medicine: evaluation of pharmacokinetic properties in special populations. J. Pharm. Sci.2011; 100:53-58.

[19]. Aagaard L., Weber C.B., Hansen E.H. Adverse drug reactions in the paediatric population in Denmark: a retrospective analysis of reports made to the Danish Medicines Agency from 1998 to 2007. Drug Saf. 2010; 33:327-339.

[20]. Napoleone Children and ADRs [Adverse Drug Reactions] Ital. J. Pediatr. 2010;36:4

[21]. Patel RM, Marfatia YS. Clinical study of cutaneous drug eruptions in 200 patients. Indian J Dermatol Venereol Leprol 2008;74:80.

[22]. Sharma VK, Sethuraman G, Kumar B. Cutaneous adverse drug reactions: Clinical pattern and causative agents-A six-year series from Chandigarh, India. J Postgrad Med 2001; 47: 95-9

[23]. Pudukadan D, Thappa DM. Adverse cutaneous drug reactions: Clinical pattern and causative agents in a tertiary care center in South India. Indian J Dermatol Venereal Leprol 2004; 70:20-4.

[24]. Ghosh S, Acharya LD, Rao PGM. Study and evaluation of the various cutaneous adverse drug reactions in Kasturba hospital, Manipal. Indian J Pharm Sci. 2006; 68(2): 212-2

[25]. Naranjo CA, Busto U, Sellers EM, Sandor P, Ruiz I, Roberts EA, et al. A method for estimating the probability of adverse drug reactions. Clin Pharmacol Ther. 1981;30:239-45

[26]. Hartwig SC, Siegel J, Schneider PJ. Preventability and severity assessment in reporting adverse drug reactions. Am J Hosp Pharm. 1992;49:2229-32

[27]. Schumock GT, Seeger JD, Kong SX. Control charts to monitor rates of adverse drug reactions. [1091-2, 1095-6].Hosp Pharm. 1995;30:1088. 
[28]. Schumock GT, Thornton JP. Focusing on the preventability of adverse drug reactions.Hosp Pharm. 1992;27:538.

[29]. Solensky R, Mendelson LM. Systemic reactions to antibiotics. Immunol Allergy Clin N Am 2001;21:679-97

[30]. Leape LL, Troyen AB, Laird N, Lawthers AG, Localio AR, Barnes BA, et al. The nature of adverse events in hospitalized patients. Results of the Harvard Medical Practice Study II. N Engl J Med 1991;324:377-84.

[31]. Hafner JW, Belknap SW, Squillante MD, Bucheit KA. Adverse drug events in emergency department patients. Ann Emerg Med 2002; 39:258-67.

[32]. Noel MV, Sushma M, Guido S. Cutaneous adverse drug reactions in hospitalized patients in a tertiary care centre. Indian J Pharmacol 2004; 36:292-5. 